\title{
Hope and Worry: Gendered Emotional Geographies of Climate Change in Three Vulnerable U.S. Communities ${ }^{\mathscr{C}}$
}

\author{
Margaret V. DU Bray, Amber Wutich, AND Alexandra Brewis \\ School of Human Evolution and Social Change, Arizona State University, Tempe, Arizona
}

(Manuscript received 6 July 2016, in final form 7 November 2016)

\begin{abstract}
Climate scientists have proposed that many people have not yet felt the results of climate change. This explains, at least in part, why some people are so unmotivated to make changes to mitigate climate change. Yet, a range of studies focused on other types of weather-related anticipated and experienced disasters, such as drought, clearly demonstrate that climate-related phenomena can elicit strong emotional reactions. Using a combination of open-ended interview questions and close-ended survey questions, the authors conducted semistructured interviews in three biophysically vulnerable communities (Mobile, Alabama; Kodiak, Alaska; and Phoenix, Arizona). The relatively high number of respondents who expressed sadness and worry at the possible outcomes of climate change indicates emotional awareness, even among climate change skeptics. The patterns were significantly gendered, with men across the three sites less likely to indicate hope. Results suggest that emotional aspects of climate change might provide an entry point for rallying vulnerable U.S. communities to consider mitigation efforts.
\end{abstract}

\section{Introduction}

Climate scientists argue that individuals and communities do not yet feel the results of climate change (Akerlof et al. 2013), explaining why rallying people to engage in mitigation efforts and investments is so difficult. Yet, a range of studies focused on other types of weather-related anticipated and experienced disasters, such as drought, clearly demonstrate that climaterelated phenomena can elicit strong emotional reactions (Sartore et al. 2007, 2008a,b; Bell et al. 2010; Farbotko and McGregor 2010; Gorman-Murray 2010; McMichael 2011; Stratford et al. 2013) and can activate energetic community action (Ryan 2016).

In an effort to connect the study of local emotion to the challenge of addressing climate change, here we ask if people's perceived climate change futures elicit any strong (positive or negative) emotions. In using interview data collected across biophysically diverse, climate-vulnerable

Supplemental information related to this paper is available at the Journals Online website: http://dx.doi.org/10.1175/ WCAS-D-16-0077.s1.

Corresponding authore-mail: Margaret V.du Bray, mvdubray@ asu.edu places across the United States, we are applying the construct of emotional geographies (Anderson and Smith 2001) to understand how these responses might vary by place. Gender is a key marker of social difference and is a useful analytical lens to understand perceptions and emotional impacts in relation to climate change.

\section{Literature review}

\section{a. Emotional geographies, place, and change}

The concept of "emotional geographies" addresses the role of emotion and affect in people's place-specific everyday lives. Prior to the mid-1980s, social science had largely neglected to incorporate the study of emotion in research, preferring to focus on rational thought and behavior. Formative research (Ulrich 1983; Russell and Lanius 1984; Lutz and White 1986; Anderson and Smith 2001) argued that without the inclusion of emotion, researchers could not effectively study how people live and experience the world. Recent research on emotion demonstrates that the inclusion of emotion, even when it might be less rational, is critical to understand how individuals and communities respond to risk and to the threat of climate change (Smith and Leiserowitz 2014; Ryan 2016). These studies also show how emotion is made in specific contexts, and how geographic place is integral 
to the emotions that people experience (Woodward and Lea 2010; Morales and Harris 2014; Goldin 2015).

The concept of emotional geography has emerged as a means to interrogate these connections. For example, water scarcity and changes in water access impact the emotional expressions of community members in waterscarce Bolivia. The hardships associated with water access often result in feelings of fear, worry, bother, and anger, and researchers found that these experiences were not equitably distributed among community members (Wutich and Ragsdale 2008). Similarly ethnographic interviews with women in Bangladesh reveal that respondents suffer emotionally because they both have difficulty attaining water (suffering for water) and often experience ill health as a result of the quality of their water (suffering from water; Sultana 2011, 2015).

Exploring the emotional dimension of resource access and management is a prime dimension of this growing field. Recent scholarship has explored the way that fishermen in Scotland build an emotional connection to their landscape through the act of fishing itself (Nightingale 2013). Additional studies in forestry management in India (Singh 2013) and changing agricultural values among farmers in South Africa (Goldin 2015) illustrate the ways that landscapes are integral in positively and negatively shaping the emotions of the people living and working on them. Shifts in these landscapes and their management can have the effect of widening social divisions and causing frustration among certain social groups, or it can have an empowering effect and introduce hope to a context where it had previously been absent (Morales and Harris 2014; Goldin 2015).

Other researchers have explored the ways that emotion becomes entrenched in where people live, including in urban spaces (Munt 2012; Harris 2014), rural villages (Pini et al. 2010; Rigby et al. 2011), and homeless shelters (Daya and Wilkins 2013). Such studies all show how place can create strong emotional ties and elicit emotional expressions. While emotional geography has been used to understand how people experience and relate to place, these analyses have not much considered what happens as places change or are anticipated to changesuch as with climate change. Because a broader environmental psychology literature (Connor et al. 2004, Higginbotham et al. 2006; Albrecht et al. 2007; Sartore et al. 2007, 2008a,b) has documented how actual landscape changes can lead to emotional devastation, we could expect that anticipated changes also will elicit emotional distress.

\section{b. Environmental geographies and gender}

Emotional geographies related to climate change could vary markedly across sites, but also within sites by key social differentiators, like gender. The literature focusing on environmental concern suggests that women will have increased emotional response to climate change compared to men. Several studies have suggested that women show a higher level of concern for the environment (Larson et al. 2011; McCright and Dunlap 2011; McCright and Sundström 2013). Much of this research has also explored the ways that men and women perceive environmental risks; as Stern et al. (1993) note, women are more likely to believe that environmental quality directly affects their well-being. As the review from Momsen (2000) demonstrates, however, the differences in environmental concern between men and women may not be particularly significant.

In contexts where there are clear differences between men and women in environmental concern, as in McCright and Dunlap's (2011) research, it seems that men, and particularly the group of white, conservative men interviewed by McCright and Dunlap, feel that they are less vulnerable in general, and in particular, are less vulnerable to the effects of environmental change. As Marshall et al. (2006) demonstrate, because white men are relatively immune to systemic injustice and harms, they, unlike their female and minority counterparts, are more willing to accept a certain amount of environmental risk. Given the minimal knowledge about emotional responses to anticipated landscape changes and the way this might impact men and women differently, we pose the following questions.

\section{Research questions and design}

Drawing on research in emotional geographies, we ask how emotional responses to climate change vary across sites with different experiences and projected outcomes as a result of climate change. Second, drawing on previous scholarship exploring differences in environmental concern between men and women, we ask whether men or women were more likely to express emotions across these three sites. This study employs a comparative analysis of interview data collected with respondents across the three sites, differentiated by gender. We identified three biophysically diverse, climate-vulnerable places within the United States as the sites for this ethnographic study. Each represents a distinct kind of vulnerability to climate change risk within the continental United States (see Table 1). For Mobile, Alabama, this is hurricanes and tropical storms; in Kodiak, Alaska, this is sea level rise and the effects of ice melt; in Phoenix, Arizona, this is drought. Data collection sites within each area were identified based on availability of ethnographic experts and other 
TABLE 1. Site characteristics.

\begin{tabular}{|c|c|c|c|}
\hline & Mobile, AL & Kodiak, AK & Phoenix, AZ \\
\hline Avg high/low temp $\left({ }^{\circ} \mathrm{F}\right)$ & $77.4 / 57$ & $46.8 / 40.8$ & $86.8 / 63.4$ \\
\hline Avg annual precipitation (in.) & 66.12 & 75.35 & 8.03 \\
\hline Natural disaster & $\begin{array}{l}\text { Hurricanes, tropical } \\
\text { storms, tornadoes }\end{array}$ & Earthquakes, tsunamis & Wildfire, drought \\
\hline Environmental issues & $\begin{array}{l}\text { Coastal erosion, } \\
\text { flooding, water } \\
\text { pollution (sewage } \\
\text { leakage, oil spills) }\end{array}$ & $\begin{array}{l}\text { Coastal erosion, ocean } \\
\text { acidification, species } \\
\text { decline }\end{array}$ & $\begin{array}{l}\text { Soil erosion, dust } \\
\text { storms, urban heat } \\
\text { island, flash floods, }\end{array}$ \\
\hline Climate & Subtropical & Subpolar oceanic & Subtropical desert \\
\hline
\end{tabular}

knowledgeable insiders to assist with tool development and interpretation.

\section{Study sites}

\section{a. Alabama}

Mobile, Alabama, is located in the southeastern United States directly along the Gulf of Mexico. A medium-sized coastal city, Mobile itself has a population of approximately 195000 people (see Tables 1,2). There are many smaller towns and fishing villages within a 100 -mi radius of Mobile that utilize the services of Mobile itself. The Gulf Coast region of Alabama has a long history of commercial fishing; the area serves as a hatchery for many species of fish (Barbier 2011; Sumaila et al. 2012) and is well known for producing a large volume of oysters and shrimp. The area has also traditionally been composed of agricultural land; while this is changing as more people move the area and it urbanizes, there are still farmers involved in cultivating produce and other crops.

The area is susceptible to hurricanes, and certain hurricanes (Hurricane Camille in 1969, Hurricane Ivan in 2004, and Hurricane Katrina in 2005) are considered by local residents to be particularly devastating (de Vries 2011). In the next 80 years, the southeastern coast of the United States is expected to see a $2^{\circ}-2.5^{\circ} \mathrm{C}$ temperature increase and a $5 \%$ decrease in overall precipitation (IPCC 2007). Because this is a coastal area that is already biophysically vulnerable to the effects of tropical storms and hurricanes, it is expected that climate change will intensify this vulnerability and increase the likelihood of coastal erosion, changes in ocean acidification, and sea level rise (IPCC 2007).

\section{b. Alaska}

Kodiak Island is in southern Alaska, separated from mainland Alaska by the Shelikof Strait. The town of Kodiak is the main town of seven rural villages on the island. The town itself has a population of just over 6000 people, many employed in the local fishing or wilderness guiding industries (see Tables 1,3). Salmon and halibut provide the livelihood for commercial fishermen and also provide subsistence for both Alaska Natives and Anglo community members (Carothers 2008; Carothers et al. 2010). The island has been inhabited for over 7000 years

TABLE 2. Respondent characteristics in Alabama $(n=31)$.

\begin{tabular}{|c|c|c|}
\hline Demographics & Frequency & Percentage $(\%)$ \\
\hline \multicolumn{3}{|l|}{ Gender } \\
\hline Female & 13 & 41.9 \\
\hline Male & 18 & 58.1 \\
\hline \multicolumn{3}{|l|}{ Race/ethnicity } \\
\hline White & 31 & 100 \\
\hline \multicolumn{3}{|l|}{ Political affiliation } \\
\hline Democrat & 1 & 3.2 \\
\hline Republican & 12 & 38.7 \\
\hline Independent/none & 18 & 58 \\
\hline \multicolumn{3}{|l|}{ Belief in climate change } \\
\hline Yes & 22 & 71 \\
\hline No & 9 & 29 \\
\hline \multicolumn{3}{|l|}{$\begin{array}{l}\text { Belief in anthropogenic } \\
\text { climate change }\end{array}$} \\
\hline Yes & 17 & 55 \\
\hline No & 13 & 42 \\
\hline \multicolumn{3}{|l|}{ Religion } \\
\hline Christian & 23 & 74.2 \\
\hline None & 6 & 19.4 \\
\hline Other & 2 & 6.5 \\
\hline \multicolumn{3}{|l|}{ Employment } \\
\hline Off the land (e.g., fisherman) & 5 & 16.1 \\
\hline Not off the land (e.g., teacher) & 18 & 58.1 \\
\hline $\begin{array}{l}\text { Other/none (e.g., stay at } \\
\text { home mom) }\end{array}$ & 8 & 25.8 \\
\hline \multicolumn{3}{|l|}{ Hope } \\
\hline Present & & 12.9 \\
\hline Absent & & 87.1 \\
\hline \multicolumn{3}{|l|}{ Worry } \\
\hline Present & 14 & 45.2 \\
\hline Absent & 17 & 54.8 \\
\hline \multicolumn{3}{|l|}{ Sad } \\
\hline Present & 14 & 45.2 \\
\hline Absent & 17 & 54.8 \\
\hline \multicolumn{3}{|l|}{ Prepared } \\
\hline Present & 5 & 83.9 \\
\hline Absent & 26 & 16.1 \\
\hline \multicolumn{3}{|l|}{ Negative } \\
\hline Present & 2 & 6.5 \\
\hline Absent & 29 & 93.5 \\
\hline
\end{tabular}


TABLE 3. Respondent characteristics in Alaska $(n=36)$.

\begin{tabular}{|c|c|c|}
\hline Demographics & Frequency & Percentage $(\%)$ \\
\hline \multicolumn{3}{|l|}{ Gender } \\
\hline Female & 23 & 63.9 \\
\hline Male & 13 & 36.1 \\
\hline \multicolumn{3}{|l|}{ Race/ethnicity } \\
\hline White & 25 & 69.4 \\
\hline Alaska Native & 5 & 13.9 \\
\hline Hispanic & 1 & 2.8 \\
\hline Asian & 1 & 2.8 \\
\hline \multicolumn{3}{|l|}{ Political affiliation } \\
\hline Democrat & 7 & 19.4 \\
\hline Republican & 6 & 16.7 \\
\hline Independent/none & 23 & 63.9 \\
\hline \multicolumn{3}{|l|}{ Belief in climate change } \\
\hline Yes & 31 & 88 \\
\hline No & 4 & 11 \\
\hline \multicolumn{3}{|l|}{$\begin{array}{l}\text { Belief in anthropogenic } \\
\text { climate change }\end{array}$} \\
\hline Yes & 24 & 69 \\
\hline No & 11 & 31 \\
\hline \multicolumn{3}{|l|}{ Religion } \\
\hline Christian & 10 & 27.8 \\
\hline None & 21 & 58.4 \\
\hline Other & 5 & 13.9 \\
\hline \multicolumn{3}{|l|}{ Employment } \\
\hline Off the land (e.g., fisherman) & 8 & 22.2 \\
\hline Not off the land (e.g., teacher) & 26 & 72.2 \\
\hline $\begin{array}{l}\text { Other/none (e.g., stay at } \\
\text { home mom) }\end{array}$ & 2 & 5.6 \\
\hline \multicolumn{3}{|l|}{ Hope } \\
\hline Present & & 36.1 \\
\hline Absent & 23 & 63.9 \\
\hline \multicolumn{3}{|l|}{ Worry } \\
\hline Present & 16 & 44.4 \\
\hline Absent & 20 & 55.6 \\
\hline \multicolumn{3}{|l|}{ Sad } \\
\hline Present & 14 & 38.9 \\
\hline Absent & 22 & 61.1 \\
\hline \multicolumn{3}{|l|}{ Prepared } \\
\hline Present & 0 & 0 \\
\hline Absent & 36 & 100 \\
\hline \multicolumn{3}{|l|}{ Negative } \\
\hline Present & 9 & 25 \\
\hline Absent & 27 & 75 \\
\hline
\end{tabular}

by Alaska Natives; while there are several groups that trace their ancestry on Kodiak Island, the most prominent nation is the Sugpiaq Alutiiq group, who continue to live and work on the island (Carothers 2010).

The IPCC (2007) reports that Alaska has already seen some of the most dramatic warming. From 1970 to 2004, average temperatures in much of Alaska have risen $2^{\circ}-3.5^{\circ} \mathrm{C}$, and scientists report that there have already been wide-scale changes in marine and freshwater biological systems in the polar regions. In the next 80 years, the IPCC (2007) suggests that the southern region of Alaska will experience a temperature increase of $2.5^{\circ}-4^{\circ} \mathrm{C}$.
Similarly, while the area currently receives an average of $75 \mathrm{in}$. of precipitation annually, the IPCC (2007) suggests that precipitation in this area will become much more variable; winter precipitation may increase by $10 \%$, while summer precipitation may increase by up to $5 \%$. Unlike much of the Arctic, however, as an island Kodiak is buffered from many of the more extreme outcomes that are likely to affect other parts of Alaska. While indigenous ways of life are expected to be vulnerable to climatic changes in Kodiak as in other regions of Alaska, the precipitation and temperature changes are likely to be less severe, with lower overall meteorological changes as a result of being buffered by the surrounding ocean. Additionally, because Kodiak is more temperate than many of the towns and villages in the further north regions of Alaska, permafrost melt and the associated infrastructure damages are less likely to impact residents in Kodiak.

\section{c. Arizona}

Phoenix, Arizona, is in the southwestern United States and has a population of 4.3 million people, making it the sixth-largest city in the United States. There are multiple sources of income for those living in the area; among the most profitable industries are the airline industry, various upcoming tech companies, and Arizona State University (see Tables 1,4). Traditionally, the Phoenix metropolitan area was a center for agriculture and animal husbandry, although mining was also profitable. In spite of high heat (Phoenix averages $\geq 37.8^{\circ} \mathrm{C}$ between June and September), dairy farming and the raising of beef cattle was quite common in the area until the 1960s. Additionally, many farmers successfully grew and exported crops. While the urbanization of the valley has displaced many of these historical activities, agriculture still remains a core value in the area.

Many residents of the Phoenix area are already biophysically vulnerable in the summers; the National Weather Service issues a heat warning at $37.8^{\circ} \mathrm{C}$, which is the average daily high in Phoenix for three months of the year. During the summer months, however, average temperatures regularly exceed $38^{\circ} \mathrm{C}$ (Baker et al. 2002) for at least $6 \mathrm{~h} \mathrm{day}^{-1}$. While many residents of Phoenix have air conditioning, the most socioeconomically vulnerable may not, and all residents are nevertheless vulnerable to the preexisting climatic conditions of Phoenix (Harlan et al. 2006; ADHS 2014). Climate change in the next 80 years is predicted to produce a $3.5^{\circ}-4.0^{\circ} \mathrm{C}$ increase in temperature for the Phoenix area. Changes in precipitation over the next 80 years will likely result in an overall warmer and drier climate, which may severely hinder access to freshwater resources (IPCC 2007). As a result of its already arid climate, Phoenix is expected to 
TABLE 4. Respondent characteristics in Arizona $(n=36)$

\begin{tabular}{|c|c|c|}
\hline Demographics & Frequency & Percentage $(\%)$ \\
\hline \multicolumn{3}{|l|}{ Gender } \\
\hline Female & 17 & 47.2 \\
\hline Male & 19 & 52.8 \\
\hline \multicolumn{3}{|l|}{ Race/ethnicity } \\
\hline White & 23 & 63.9 \\
\hline Black & 3 & 8.3 \\
\hline $\begin{array}{l}\text { American Indian/Native } \\
\text { American }\end{array}$ & 2 & 5.6 \\
\hline Hispanic & 5 & 13.9 \\
\hline Asian & 1 & 2.6 \\
\hline Mixed/multiple & 2 & 5.6 \\
\hline \multicolumn{3}{|l|}{ Political affiliation } \\
\hline Democrat & 11 & 30.6 \\
\hline Republican & 6 & 16.7 \\
\hline Independent/none & 19 & 52.8 \\
\hline \multicolumn{3}{|l|}{ Belief in climate change } \\
\hline Yes & 32 & 88 \\
\hline No & 4 & 11 \\
\hline \multicolumn{3}{|l|}{$\begin{array}{l}\text { Belief in anthropogenic } \\
\text { climate change }\end{array}$} \\
\hline Yes & 26 & 74 \\
\hline No & 9 & 25 \\
\hline \multicolumn{3}{|l|}{ Religion } \\
\hline Christian & 17 & 47.2 \\
\hline None & 15 & 41.6 \\
\hline Other & 4 & 11.1 \\
\hline \multicolumn{3}{|l|}{ Employment } \\
\hline Off the land (e.g., dairyman) & 3 & 8.3 \\
\hline Not off the land (e.g., teacher) & 27 & 75 \\
\hline $\begin{array}{l}\text { Other/none (e.g., stay at } \\
\text { home mom) }\end{array}$ & 6 & 16.7 \\
\hline \multicolumn{3}{|l|}{ Hope } \\
\hline Present & 5 & 13.9 \\
\hline Absent & 31 & 86.1 \\
\hline \multicolumn{3}{|l|}{ Worry } \\
\hline Present & 11 & 30.6 \\
\hline Absent & 25 & 69.4 \\
\hline \multicolumn{3}{|l|}{ Sad } \\
\hline Present & 12 & 33.3 \\
\hline Absent & 24 & 66.7 \\
\hline \multicolumn{3}{|l|}{ Prepared } \\
\hline Present & 1 & 2.8 \\
\hline Absent & 35 & 97.2 \\
\hline \multicolumn{3}{|l|}{ Negative } \\
\hline Present & 1 & 2.8 \\
\hline Absent & 35 & 97.2 \\
\hline
\end{tabular}

see increased intensity and duration of heat waves with considerable concerns for human health outcomes (IPCC 2007).

\section{Methods}

\section{a. Participant observation}

Early participant observation at each site provided information about local community concerns and livelihood strategies and provided context for subsequent keyword analysis (DeWalt and DeWalt 2002). In Mobile, this included spending time in the local fishermen's Baptist church and talking informally with local residents in the greater Mobile area. In Kodiak, an ongoing research project (Donkersloot and Carothers 2016) was the point of community entry. Additional participant observation included volunteering with local community members and building rapport with local families. In Phoenix, participant observation activities included talking with a variety of local stakeholders, such as water managers and land owners. Data from participant observation, captured in field notes, provide a context for characterizing the field sites and interpreting larger themes.

\section{b. Questionnaire design and data collection}

We developed a combined interview and survey instrument composed of 16 open-ended interview questions with predetermined probes, as well as 21 survey questions (see Appendix 1 in the online supplemental material). To ensure content validity, we used previously tested survey questions and extensively tested the protocol using cognitive interviewing strategies (DeMaio and Rothgeb 1996) in one of the sites (Phoenix).

Data were collected using a nonprobabilistic, purposive sampling strategy in each of the three communities described above (Bernard and Ryan 2009). To develop an in-depth understanding of the range of experiences and views on climate change in each of these three locations beyond gender, we sampled within the populations of each of the three cities to capture a range of professions, race/ethnicities, and political views. Because the gender comparison is a central component of this research, we also attempted to interview an equal number of men and women in each location. While the sample was not stratified, we attempted to gain insight from as many groups as possible in each location (Guest 2014).

In accordance with Guest et al.'s (2006) research indicating that 6-12 interviews would allow researchers to reach thematic saturation, we conducted at least 30 interviews in each location. We purposefully oversampled because of the range of experiences and concerns between these sites per Hagaman and Wutich's (2016) recommendation regarding metatheme saturation in multisited research. Respondents were sampled in public places, including coffee shops, libraries, and parks, as well as work locations. Sampling in public locations allows researchers to capture a sample that has shared understandings of environmental and cultural beliefs and practices (Handwerker and Wozniak 1997). In some instances, sampling at work places was 
necessary in order to increase the diversity and representativeness of the sample (Guest 2014).

\section{c. Data analysis}

To analyze the interview data, we used a keywords-incontext (KWIC) approach to explore the emotional responses to climate change experienced by respondents. Using lists of preestablished emotion words and using guidance from other KWIC studies (Ryan and Weisner 1998; Seale et al. 2006; Saldaña 2009; Taylor et al. 2015), we used an automated coding procedure to identify emotion words in each interview. The coding unit for this study was at the word level; thus, within each question, and therefore, within each interview, emotion words could occur multiple times, leading to total counts by respondent. Emotion word codes were not mutually exclusive to ensure that we understood the full context of the emotional response.

Once the coding was complete, we examined each interview to explore how each emotion word was used; common themes emerged deductively as a result of the pattern of questioning. The most common themes that emerged from these interviews include emotional responses to the current effects of climate change, the anticipated effects on livelihoods, and the way climate change will affect the younger generation. To run statistical tests, we dichotomized emotion words into presence and absence by interview. Additionally, emotion words were grouped into positive, negative, and neutral categories to understand if men and women were more likely to fall into one end of the emotional spectrum or the other. Exemplar quotes were selected using strategies from Ryan and Bernard (2003), including looking for similarities and differences and patterns of repetition.

After the initial coding phase, we performed further quantitative analyses to explore the way emotion word usage varied within and between the sites. First, using both ANOVA and Mann-Whitney $U$ tests, we explored the way that emotion word usage varied between the sites to assess the degree to which emotional expression might be the result of local ecological variability. We used chisquare tests to examine how emotion word use varied across the sites by gender. Using $t$ tests, we looked at how emotional expression differed by gender and site. Finally, $t$ tests and Mann-Whitney $U$ tests analyzed the valence of emotions expressed by men and women by site.

\section{Results}

\section{a. Cross-site differences in emotion words in context}

Across the three sites, the two most commonly used emotion words were "worry" and "sad." These words occur with relatively equal frequency across the sites (see
Fig. 1). While these words were used in different contexts, respondents regularly indicated that they felt sad for the younger generation because they would not have the same opportunities, or worried for them because their lives would be so much different than their own. Respondents with children often said they felt sad that their children would not be able to see the same wildlife and resources that they had. As one Alabama resident noted, "I don't really know that I could say I'm worried, because it doesn't really affect me... I think you just hope it won't affect your grandchildren down the road."

Respondents also used "worry" and "sad" to describe changes to the landscape in their area; for some respondents this included a change in their resource access (see Fig. 1). For this Alaska resident, this was certainly the case: "It makes me sad ... I love that fishing is a way of life here, and I think it produces the unique and valuable mentality that the people and resources of the earth are constantly at a delicate balance." Several respondents in each site identified changes to local seasonality, which meant that they might not be able to continue in their current work. Respondents who engaged in living off the land evoked sadness and worry in the context of losing their livelihoods or in not being able to give their children the same livelihood opportunities in the future.

\section{b. Emotion words in context: Results from Alabama, Alaska, and Arizona}

\section{1) Alabama}

Although fishing and seafood handling is still a common profession among people in smaller villages around Mobile, Mobile itself is a community built on diverse industries. It is a major shipping port along the Gulf Coast and also houses a major university. Respondents in the area are fairly politically conservative; while there are small pockets where this is not the case, many of the respondents identified as conservatives or as Republicans (see Table 1). Perhaps as a result, a large volume of responses that indicated that respondents did not believe in anthropogenic climate change. Because the area has its roots in the fishing and farming industries, most of the respondents interviewed indicated that they had a strong connection to their local environment. Although $43 \%$ of respondents did not believe that climate change was anthropogenic, these respondents still showed a level of concern for the future of their area as the landscape changed.

Respondents in Alabama were significantly more likely $\left(\chi^{2}=8.84, p=0.012\right.$, phi $\left.=0.293\right)$ to use the word "prepared" compared to other sites; these respondents indicated that they felt prepared for the possibilities of climate change in their area (see Table 4). However, 


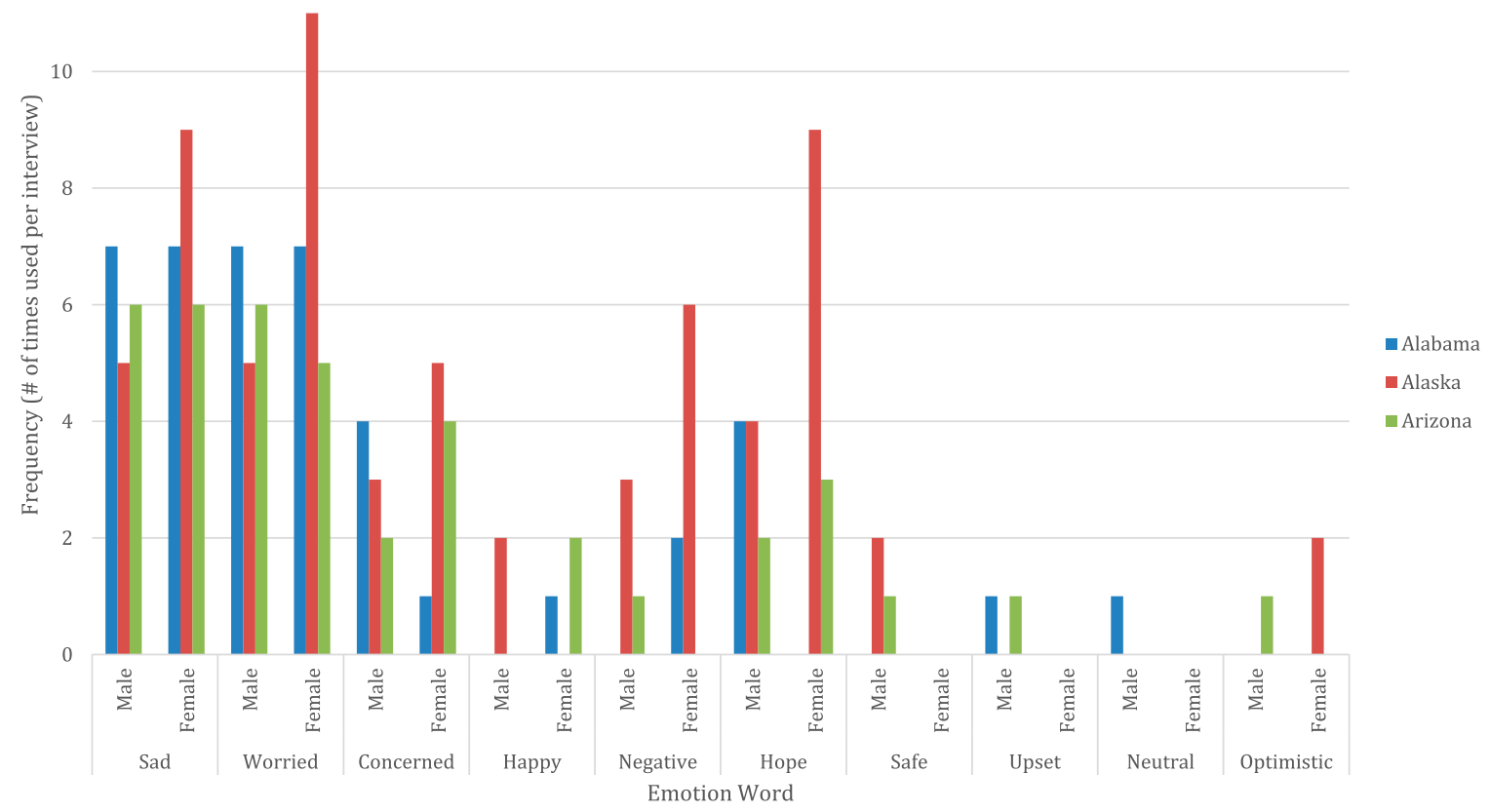

FIG. 1. Graph showing emotion word usage by site and gender.

while these respondents did indicate a feeling of preparedness, no respondents used the word "safe," suggesting that while respondents feel they can handle the future possibilities of climate change, they do not feel immune to those possibilities. This feeling is typified by the following quote: "It concerns me-I have deep feelings for people whose lives are torn up, but in reality, my feelings in that direction are not as intense as they are in relation to hurricanes and storm water runoff, which are only going to get worse by climate change. There are so many things that we don't know. We adapt. We've always adapted. If we have climate change, we're going to do things to slow it down. We're going to adapt. The majority of the people are going to figure out how to survive." This respondent indicates a feeling that, while they are not going to be immune to the effects of climate change, they will find ways to deal with the effects. However, while this respondent indicated an ability to adapt, it is with resignation; no respondents in Alabama indicated that they were optimistic, either about the current or future prospects of climate change.

\section{2) Alaska}

The fishing industry in Kodiak has attracted a somewhat diverse pool of residents; while many of the commercial fishermen are white Anglo-Americans, there is a large Asian (predominantly Filipino) population that crews fishing vessels and works in the local canneries. Additionally, approximately $10 \%$ of the population in Kodiak and the outlying villages is composed of Alaska Natives, primarily Alutiiq members. Respondents in the area are of mixed opinions on climate changes; while there are a number of deniers of anthropogenic climate change (31\% of respondents), many respondents believe that climate change is anthropogenic. Like the respondents in the Mobile region, and regardless of opinion on anthropogenic climate change, Kodiak respondents evidenced a high level of concern for the environment and a great deal of emotion at the thought of landscape changes.

Respondents in Alaska were significantly more likely $\left(\chi^{2}=7.18, p=0.036\right.$, phi $\left.=0.264\right)$ to use the word "hope." While residents in Alabama and Arizona also said "hope," they often used it in the context of hoping that climate change would not make the climate worse (Fig. 1). Respondents in Alaska used hope both in a positive and negative context; while several people indicated that they hope that climate change does not make weather or climate worse, or that they hope they can stay in business, many of them indicated that they have hope for the future. Perhaps because of the already cool climate in Kodiak, many of these residents feel that they have a greater chance of successfully weathering the effects of climate change.

Additionally, the only group of respondents in this study to use the word "interested" was in Kodiak; this 
may also reflect a mindset of resilience to the effects of climate change as a result of being an island (see Fig. 1). One respondent indicated that climate change could bring more opportunities to the area: "I'm not an alarmist, I don't consider myself a pessimist, so I don't have any grave concerns, and right now, I'm just enjoying the benefits. A disaster for some may mean prosperity for others-as polar ice melts, we might benefit as more shipping traffic comes through this area." Unlike respondents in other locations, several respondents in Kodiak said they were optimistic or indicated that they felt safe. These respondents, though representing only a subsample of the respondent group, indicate that Kodiak may be somewhat anomalous, both in Alaska and in the United States, for its potential resilience to the impacts of climate change.

It is important to note, however, that while the use of these terms was more prominent in Alaska than the other two sites, respondents in Kodiak were also the most likely to use "negative" $\left(\chi^{2}=9.8, p=0.006\right.$, phi $=$ $0.308)$. While negative occurred with a relatively low frequency in the data (only nine respondents used negative), this nevertheless indicates that, while some respondents feel that they will be okay, or are interested in the possibilities presented by climate change, there are still other who feel that there will be negative consequences, particularly on resource access and therefore the local economy.

\section{3) ARIZONA}

The diverse economic opportunities in the Phoenix metropolitan area have attracted a similarly diverse population. While $73 \%$ of the population is white, up to $30 \%$ are Hispanic citizens, and smaller groups of other populations are present. Perhaps because of the conservative political climate of the area, $26 \%$ of respondents in the Phoenix area indicated that they did not believe in anthropogenic climate change, and while there were some respondents who indicated concern and other feelings as a result of the possibilities of climate change, overall, respondents appeared to be less emotional about the current state of climate change and the way it could affect them or their community (see Fig. 1).

Overall, respondents in Phoenix were the least likely of the three groups of respondents to indicate an emotional reaction to the effects and possibilities of climate change (Fig. 1). While respondents did indicate that they felt sadness or were worried about the possible outcomes of climate change with an equal frequency to the other sites, they had fewer overall emotional responses, positive or negative, to the realities and future of climate change in their area (see Fig. 1). Several respondents indicated concern for the younger generation: " $[\mathrm{I}$ am $]$ Sad and concerned that they won't have the same experience I had. They won't be aware of the polar bears and that it'll be like dinosaurs like "what is that?", However, for many respondents, while they indicated that they felt the climate would change, few of them used emotion words: "It is inevitable, not very optimistic. The existing patterns of consumption are entrenched and ingrained. It will be hard to reverse, politically. It will require a severe disruption like [changes to] the water supply, and ocean levels." The lack of emotion word usage seems puzzling given that Phoenix already has an extreme climate; however, perhaps because of that, people express resignation or are unconcerned about living in an area that will get warmer and drier because of their experiences in an already warm and dry climate. Additionally, because many respondents in the Phoenix area are buffered from the local ecology by the surrounding city, there may be less awareness of changing conditions, resulting in less emotional distress.

\section{Gendered differences in emotion words in context}

Data were analyzed by gender, both across the United States and within each site to check for variance in responses (see Figs. 2, 3). Across the United States, men and women were equally likely to use "worry" and "sad"; although fewer men than women were likely to evoke sadness, they were more likely to indicate worry (see Fig. 2). Women commonly indicated that they were sad for the future generation; this was often expressed as sadness that their children would not have the same opportunities or would not be able to experience the world as they did as children.

For men, the use of worry was often related to financial survival. Men were also worried about outcomes for the future generation, but they often indicated their worries in the context of their livelihood and the local economy, particularly as it related to changes in local ecology. As this one male respondent noted, "I feel uncertainty-not trepidation, but in one way or another, our society and civilization will adapt in a way that's positive, at least in the short term, over the next 500 years or so. Not fear, trepidation, not total pessimism. Some changes, depending on where you live, there might be positive changes, especially with resources-fish populations - we can capitalize on; some new populations will be useful, others will no longer be available. No doomsday scenario-changes subtle and prolonged enough - adaptation will be by happenstance long-term changes-hard for people to comprehend." His concern 


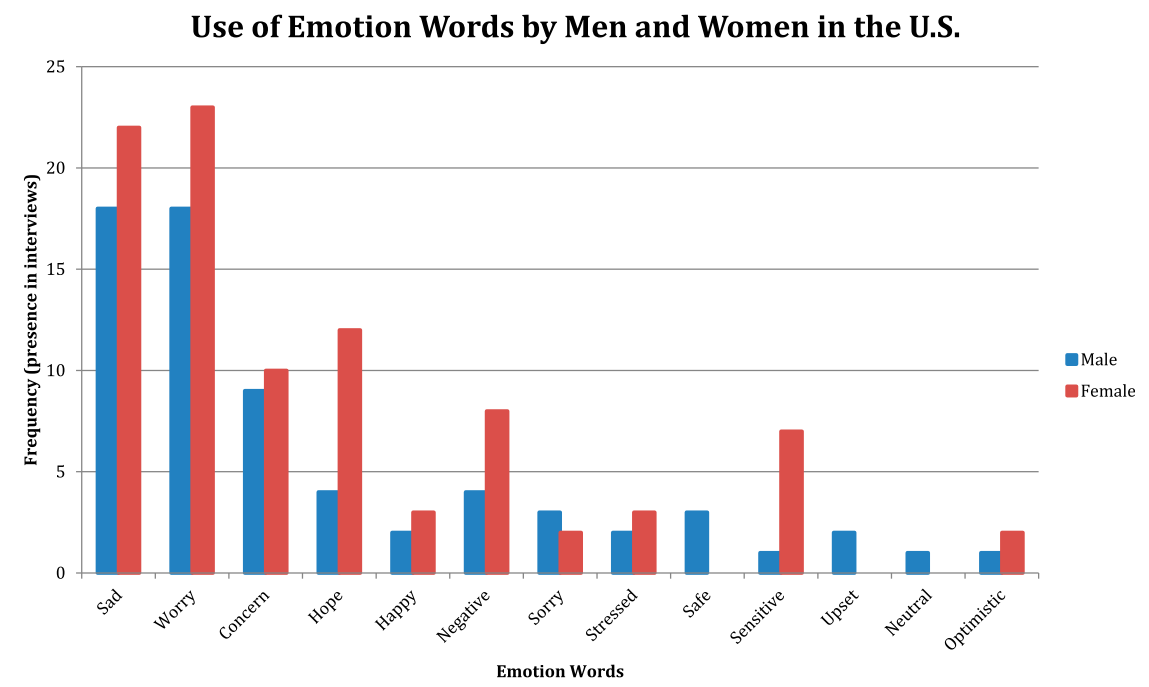

FIG. 2. Graph showing the number of interviews where emotion words were used by men and women, respectively.

occurs alongside a belief that his location and community will be okay, even as the changes occur.

Across the three United States sites, women were significantly more likely to use "hope" $\left(\chi^{2}=4.042\right.$, $p=0.044$, phi $=-0.22)$. Because women were also more likely than men to indicate that they were sad, this indicates an interesting schism in the way women may think about the effects of climate change. Women were sad for the younger generation, but many of them also indicated that they had hope for the younger generation, or hoped that the younger generation would be able to find a way to mitigate the effects of climate change. Sadness for the younger generation was a theme repeated among female respondents, as exemplified by this response: "It makes me feel sad for them because they will have to be the ones to put in the effort." While

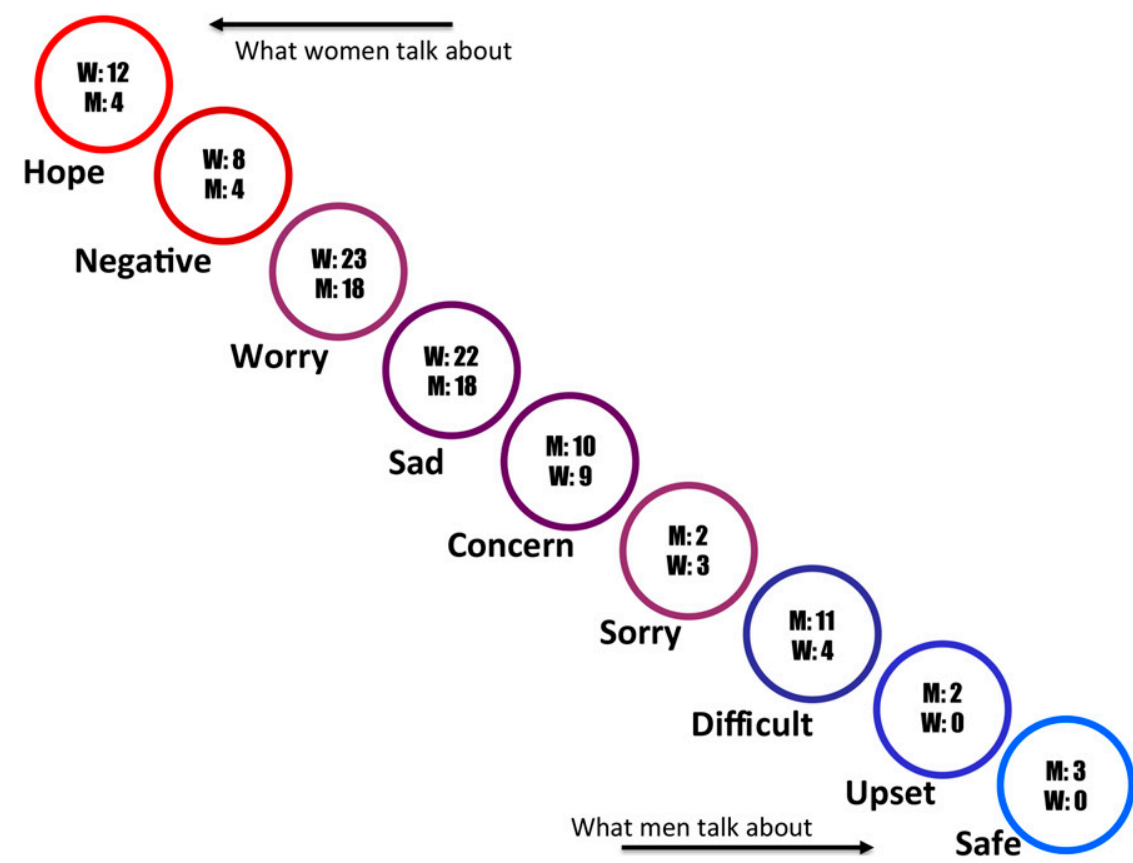

FIG. 3. We analyzed 103 interviews across the three sites by gender to show which emotion words were most commonly used by women and which emotion words were most commonly used by men. 
this particular respondent did not use "hope" directly, she nevertheless indicates a sense that the younger generation may be equipped to handle the effects of climate change, even while indicating a sorrow at leaving challenging circumstances to them. Thirteen percent of female respondents evoked these emotions simultaneously (in contrast, only one male respondent used these emotions together), indicating that there may be a tension in the way women feel about the effects and future possibilities of climate change.

When the data were analyzed by site and by gender, no statistically significant results were found, indicating that while patterns differ in the way women and men experience emotions across the United States, within sites, gender was not a strong factor in the way emotions were expressed.

\section{Discussion}

While the context in which respondents used these words varied across three very different U.S. sites, responses from each site indicate negative emotional reactions to the current effects and future possibilities of climate change: $65 \%$ of respondents indicated that they felt "worried" or "sad" about climate change. While these responses may not be rational considering that communities may not yet be experiencing the effects of climate change, these responses are nevertheless both justified and important to take into consideration to understand how people are experiencing the current and future effects of climate change and to understand how they make decisions based on these emotions (Smith and Leiserowitz 2014; Ryan 2016).

In Alaska and Alabama, which have more moderate climates and a more recent history of resource exploitation through fishing and other economic opportunities, "sad" and "worry" were used more in the context of worrying about the loss of income from traditional economic activities or sadness about the ability to pass on traditional livelihoods to children. In Alaska, in particular, respondents indicated a level of sadness as a result of watching their local ecology change. Because these two areas have climates that allow respondents to work and recreate outside year-round, it is possible that respondents in these locations are more aware of the changes already occurring on their landscapes. In contrast, while many respondents in Arizona indicated worry or sadness for the younger generation, few respondents used negative emotional terms to describe changes to the landscape. Because Phoenix has an inhospitable climate from the months of May to September, it may be that respondents spend less time outside and may be less aware of changes to their local ecology.
The large urban environment in Phoenix may also insulate people from local environmental changes. Additionally, because this is a climate that does already present so many challenges to living and working comfortably, it is possible that respondents in Phoenix are less concerned about the possibilities of climate change, many of which they already deal with on a daily basis, even if they do so to a lesser extent than they will in 80 years (IPCC 2007). Previous research on the effects of worry (Wutich and Ragsdale 2008; Sultana 2011) indicates that this emotional response to uncertain and difficult circumstances increases the likelihood of other negative emotional responses. Attempting to address worries of local community members earlier rather than later may allow policy makers to intervene and prevent additional concerns regarding climate change.

The results by gender offer an interesting insight into differences in how men and women may feel about the current effects and future possibilities of climate change. While researchers have already explored the way men and women express environmental concern differently (Larson et al. 2011; McCright and Dunlap 2011; McCright and Sundström 2013), our results indicate that men and women express negativity about climate change relatively equally. However, different words reflect associated emotions. While men were more likely to indicate their worry and to be worried, particularly in the context of resource access and livelihood strategies in their area, women were more likely to express sadness, particularly for the younger generation.

Not all emotions respondents expressed were negative, but differences in positive and negative emotions were often associated with differences in gender. In terms of positivity, while only male respondents indicated that they felt "safe," women were more likely to indicate that they had hope. While the indication by men that they felt safe fits with the existing literature (Marshall et al. 2006; McCright and Dunlap 2011) suggesting that men are less likely to feel vulnerable to the effects of climate change as a result of their generally higher societal status, it is not clear why women were more likely to indicate that they had hope. While Goldin (2015) explored the way women express hope in the context of new farming opportunities, the women in our study largely indicated that they had hope for the younger generation, which does not fit with Goldin's established idea of hope serving as a mechanism of "power for." Hope for the younger generation, while allowing female respondents to continue to live as they have, and to have hope for an acceptable future for the younger generation, does not give them any power to do anything. Nevertheless, hope also indicates the opportunity for policy-makers and community members to 
intervene and attempt to make constructive changes to mitigate the effects of climate change.

Indeed, the tension in women's responses that indicates that they both have hope but are more likely to indicate sadness than men resonates well with the environmental psychology literature on solastalgia (Connor et al. 2004; Higginbotham et al. 2006; Albrecht et al. 2007). It suggests that women in this study feel that their landscape is already changing to the extent that what they recognized from their childhood will not be available for their children or for other youths in the younger generation. Nevertheless, they are optimistic that the younger generation might be able to make changes that allow them to continue forward and have a good life, as they did. These women express solastalgia specifically in the context of the younger generation, so they indicate that, while it may be possible for the younger generation to live good lives, the lives that they lead may be unrecognizable to the women thinking about them now, and this results in their sadness. Indeed, these women are suffering for the consequences of climate change, although they are doing it long before the outcomes are clear (Sultana 2011).

The lack of anger expressed by respondents indicates that, unlike previous studies exploring the emotional dimensions of changing landscapes or shortages of resources, anger and fear are not commonplace emotions in discussions of climate change futures in the United States. These respondents are by and large better off than those in many of the studies exploring difficulties with resource access in developing countries (Wutich and Ragsdale 2008; Sultana 2011), and fiscal resilience can assist with emotional resilience. Additionally, few of these respondents are immediately threatened by the effects of climate change; while changing local ecology may lead to necessary changes in housing and location, these effects may not yet be salient to these respondents as they are in other locations (Farbotko and McGregor 2010; Gorman-Murray 2010; Stratford et al. 2013).

\section{Conclusions}

This research found that, while there are differences in the way that respondents in these three sites expressed their emotions as a result of climate change, there many similarities. Each of these three sites has different predicted outcomes as a result of climate change. In Alabama, residents are likely to see an increase in frequency and intensity of tropical storms and sea level rise; in Alaska, residents may see sea level rise, ocean acidification, and increased precipitation; and in
Arizona, residents may experience worsening heat and drought conditions. Perhaps because all three sites face some significant level of biophysical vulnerability, respondents in each of these three sites indicated similar responses to the current realities and future effects of climate change.

Gender comparisons indicated that women may be more optimistic about the future than men. The relatively high number of respondents who expressed sadness and worry at the possible outcomes of climate change indicates that there is an undercurrent of climate change awareness and concern in these sites that may allow policy-makers to work with community members to create policies that may mitigate the effects of climate change while also resonating with local community members. The expression of sadness and hope in these communities indicates the possibility for change and intervention that might help prevent future disasters and bolster the adaptive capacity of these communities. Charged emotional spaces offer a route for individuals and communities to work together; if respondents, and others like them in their communities, can find common ground, there may be room for changes that reflect their interests and concerns regarding climate change.

Acknowledgments. This research was conducted as part of the Global Ethnohydrology Study, a multiyear, multisite study designed to examine water norms and knowledge cross culturally. We thank our research collaborators, interviewers, and participants in each site for their contributions to the study; in particular, we thank Dr. Courtney Carothers at UAF for facilitating research opportunities and housing in Kodiak, and for providing guidance and support throughout the research process; Danielle Ringer for her hospitality and suggestions; the extended Beck-Goodell clan for their generosity and kindness; the Weeks Bay National Estuarine Research Reserve for providing housing and research support; and the customers and proprietors at Latte Da for their warm welcome and suggestions. This material is based upon work supported by the National Science Foundation (NSF) under Grant SES-0951366, DMUU: Decision Center for a Desert City II: Urban Climate Adaptation and Grant SES-1462086, DMUU: DCDC III: Transformational Solutions for Urban Water Sustainability Transitions in the Colorado River Basin. Additional support was provided by NSF Grant BCS1026865: Central-Arizona Phoenix Long-Term Ecological Research. Any opinions, findings, and conclusions or recommendations expressed in this material are those of the authors and do not necessarily reflect the views of the National Science Foundation. 


\section{REFERENCES}

ADHS, 2014: Heat Safety-Heat-related illness. Arizona Department of Health Services, accessed 25 November 2014. [Available online at http://www.azdhs.gov/phs/oeh/extreme/ heat/illness.php.]

Akerlof, K., E. W. Maibach, D. Fitzgerald, A. Y. Cedeno, and A. Neuman, 2013: Do people "personally experience" global warming, if so how, and does it matter? Global Environ. Change, 23, 81-91, doi:10.1016/j.gloenvcha.2012.07.006.

Albrecht, G., and Coauthors, 2007: Solastalgia: The distress caused by environmental change. Australas. Psychiatry, 15, (Suppl. 1), S95-98.

Anderson, K., and S. J. Smith, 2001: Editorial: Emotional geographies. Trans. Inst. Br. Geogr., 26, 7-10, doi:10.1111/ 1475-5661.00002.

Baker, L. A., A. J. Brazel, N. Selover, C. Martin, N. McIntyre, F. R. Steiner, A. Nelson, and L. Musacchio, 2002: Urbanization and warming of Phoenix (Arizona, USA): Impacts, feedbacks, and mitigation. Urban Ecosyst., 6, 183-203, doi:10.1023/ A:1026101528700.

Barbier, E. B., 2011: Coastal wetland restoration and the Deepwater Horizon oil spill. Vanderbilt Law Rev., 64 (6), 1821-1849.

Bell, J., M. Brubaker, K. Graves, and J. Berner, 2010: Climate change and mental health: Uncertainty and vulnerability for Alaska Natives. $\mathrm{CCH}$ Bulletin 3, Center for Climate and Health, 10 pp. [Available online at http://anthc.org/wp-content/ uploads/2016/01/CCH-Bulletin-No-3-Mental-Health.pdf.]

Bernard, H. R., and G. W. Ryan, 2009: Analyzing Qualitative Data: Systematic Approaches. SAGE Publications, $451 \mathrm{pp}$.

Carothers, C., 2008: 'Rationalized out': Discourses and realities of fisheries privatization in Kodiak, Alaska. Enclosing the Fisheries: People, Place, and Power, M. E. Lowe and C. Carothers, Eds., American Fisheries Society, 55-74.

_ 2010: Tragedy of commodification: Displacements in Alutiiq fishing communities in the Gulf of Alaska. Marit. Stud., 9 (2), 95-120.

— D. K. Lew, and J. Sepez, 2010: Fishing rights and small communities: Alaska halibut IFQ transfer patterns. Ocean Coast. Manage., 53, 518-523, doi:10.1016/j.ocecoaman.2010.04.014.

Connor, L., G. Albrecht, N. Higginbotham, S. Freeman, and W. Smith, 2004: Environmental change and human health in upper hunter communities of New South Wales, Australia. EcoHealth, 1 (Suppl. 2), SU47-SU58, doi:10.1007/ s10393-004-0053-2.

Daya, S., and N. Wilkins, 2013: The body, the shelter, and the shebeen: An affective geography of homelessness in South Africa. Cult. Geogr., 20, 357-378, doi:10.1177/ 1474474012469886.

DeMaio, T. J., and J. M. Rothgeb, 1996: Cognitive interviewing techniques in the lab and in the field. Answering Questions: Methodology for Determining Cognitive and Communicative Processes in Survey Research, N. Schwarz and S. Sudman, Eds., Jossey-Bass Publishers, 177-196.

de Vries, D. H., 2011: Time and population vulnerability to natural hazards: The pre-Katrina primacy of experience. Environmental Anthropology Today, H. Kopnina and E. ShoremanOuimet, Eds., Routledge, 140-160.

DeWalt, K. M., and B. R. DeWalt, 2002: Participant Observation: A Guide for Fieldworkers. Altamira Press, 266 pp.

Donkersloot, R., and C. Carothers, 2016: The graying of the Alaskan fishing fleet. Environ. Sci. Policy Sustainable Dev., 58, 30-42, doi:10.1080/00139157.2016.1162011.
Farbotko, C., and H. V. McGregor, 2010: Copenhagen, climate science, and the emotional geographies of climate change. Aust. Geogr., 41, 159-166, doi:10.1080/00049181003742286.

Goldin, J., 2015: Hope as a critical resource for small scale farmers in Mpumalanga. Human. Geogr., 8, 24-36.

Gorman-Murray, A., 2010: An Australian feeling for snow: Towards understanding cultural and emotional dimensions of climate change. Cultural Stud. Rev., 16, 60-81, doi:10.5130/ csr.v16i1.1449.

Guest, G., 2014: Sampling and selecting participants in field research. Handbook of Methods in Cultural Anthropology, H. R. Bernard and C. C. Gravlee, Eds., Rowman \& Littlefield, 215-249.

_- A. Bunce, and L. Johnson, 2006: How many interviews are enough?: An experiment with data saturation and variability. Field Methods, 18, 59-82, doi:10.1177/1525822X05279903.

Hagaman, A. K., and A. Wutich, 2016: How many interviews are enough to identify metathemes in multisited and cross-cultural research? Another perspective on Guest, Bunce, and Johnson's (2006) landmark study. Field Methods, 29, 23-41, doi:10.1177/ $1525822 X 16640447$.

Handwerker, W. P., and D. F. Wozniak, 1997: Sampling strategies for the collection of cultural data: An extension of Boas's answer to Galton's problem. Curr. Anthropol., 38, 869-875, doi:10.1086/204675.

Harlan, S. L., A. J. Brazel, L. Prashad, W. L. Stefanov, and L. Larsen, 2006: Neighborhood microclimates and vulnerability to heat stress. Soc. Sci. Med., 63, 2847-2863, doi:10.1016/ j.socscimed.2006.07.030.

Harris, L. M., 2014: Imaginative geographies of green: Difference, postcoloniality, and affect in environmental narratives in contemporary Turkey. Ann. Assoc. Amer. Geogr., 104, 801815, doi:10.1080/00045608.2014.892356.

Higginbotham, N., L. Connor, G. Albrecht, S. Freeman, and K. Agho, 2006: Validation of an environmental distress scale. EcoHealth, 3, 245-254, doi:10.1007/s10393-006-0069-x.

IPCC, 2007: Climate Change 2007: Synthesis Report. Cambridge University Press, 73 pp. [Available online at https://www.ipcc. ch/pdf/assessment-report/ar4/syr/ar4_syr.pdf.]

Larson, K. L., D. C. Ibes, and D. D. White, 2011: Gendered perspectives about water risks and policy strategies: A tripartite conceptual approach. Environ. Behav., 43, 415-438, doi:10.1177/0013916510365253.

Lutz, C., and G. M. White, 1986: The anthropology of emotions. Annu. Rev. Anthropol., 15, 405-436, doi:10.1146/ annurev.an.15.100186.002201.

Marshall, B. K., J. S. Picou, C. Formichella, and K. Nicholls, 2006: Environmental risk perceptions and the white male effect: Pollution concerns among deep-South coastal residents. J. Appl. Sociol., 23 (2), 31-49.

McCright, A. M., and R. E. Dunlap, 2011: Cool dudes: The denial of climate change among conservative white males in the United States. Global Environ. Change, 21, 1163-1172, doi:10.1016/j.gloenvcha.2011.06.003.

_ in environmental concern in the Swedish general public 1990-2011. Int. J. Sociol., 43, 63-86, doi:10.2753/ IJS0020-7659430402.

McMichael, A. J., 2011: Drought, dying and mental health: Lessons from recent experiences for future risk-lessening policies. Aust. J. Rural Health, 19, 227-228, doi:10.1111/j.1440-1584.2011.01217.x.

Momsen, J. H., 2000: Gender differences in environmental concern and perception. J. Geog., 99, 47-56, doi:10.1080/ 00221340008978956 . 
Morales, M. C., and L. M. Harris, 2014: Using subjectivity and emotion to reconsider participatory natural resource management. World Dev., 64, 703-712, doi:10.1016/ j.worlddev.2014.06.032.

Munt, S. R., 2012: Journeys of resilience: The emotional geographies of refugee women. Gender Place Cult., 19, 555-577, doi:10.1080/0966369X.2011.610098.

Nightingale, A., 2013: Fishing for nature: The politics of subjectivity and emotion in Scottish inshore fisheries management. Environ. Plann., 45A, 2362-2378, doi:10.1068/a45340.

Pini, B., R. Mayes, and P. McDonald, 2010: The emotional geography of a mine closure: A study of the Ravensthorpe nickel mine in Western Australia. Soc. Cult. Geogr., 11, 559574, doi:10.1080/14649365.2010.497850.

Rigby, C. W., A. Rosen, H. L. Berry, and C. R. Hart, 2011: If the land's sick, we're sick: The impact of prolonged drought on the social and emotional well-being of Aboriginal communities in rural New South Wales. Aust. J. Rural Health, 19, 249-254, doi:10.1111/j.1440-1584.2011.01223.x.

Russell, J. A., and U. F. Lanius, 1984: Adaptation level and the affective appraisal of Environments. J. Environ. Psychol., 4, 119-135, doi:10.1016/S0272-4944(84)80029-8.

Ryan, G. W., and T. Weisner, 1998: Content analysis of words in brief descriptions: How fathers and mothers describe their children. Using Methods in the Field: A Practical Introduction and Casebook, V. C. de Munck and E. J. Sobo, Eds., Altamira Press, 57-68.

— Field Methods, 15, 85-109, doi:10.1177/1525822X02239569.

Ryan, K., 2016: Incorporating emotional geography into climate change research: A case study in Londonderry, Vermont, USA. Emotion Space Soc., 19, 5-12, doi:10.1016/j.emospa.2016.02.006.

Saldaña, J., 2009: The Coding Manual for Qualitative Researchers. SAGE Publications, $328 \mathrm{pp}$.

Sartore, G.-M., B. Kelly, and H. J. Stain, 2007: Drought and its effects on mental health: How GPs can help. Aust. Fam. Physician, 36 (12), 990-993.

,,,--- G. Albrecht, and N. Higginbotham, 2008a: Control, uncertainty, and expectations for the future: A qualitative study of the impact of drought on a rural Australian community. Rural Remote Health, 8, 950-964.

$\longrightarrow,-\longrightarrow$, J. Fuller, L. Fragar, and A. Tonna, 2008b: Improving mental health capacity in rural communities: Menta health first aid delivery in drought-affected New South
Wales. Aust. J. Rural Health, 16, 313-318, doi:10.1111/ j.1440-1584.2008.01005.x.

Seale, C., S. Ziebland, and J. Charteris-Black, 2006: Gender, cancer experience, and internet use: A comparative keyword analysis of interviews and online cancer support groups. Soc. Sci. Med., 62, 2577-2590, doi:10.1016/j.socscimed.2005.11.016.

Singh, N., 2013: The affective labor of growing forests and the becoming of environmental subjects: Rethinking environmentality in Odisha, India. Geoforum, 47, 189-198, doi:10.1016/j.geoforum.2013.01.010.

Smith, N., and A. Leiserowitz, 2014: The role of emotion in global warming policy support and opposition. Risk Anal., 34, 937948, doi:10.1111/risa.12140.

Stern, P. C., T. Dietz, and L. Kalof, 1993: Value orientations, gender, and environmental concern. Environ. Behav., 25, 322348, doi:10.1177/0013916593255002.

Stratford, E., C. Farbotko, and H. Lazrus, 2013: Tuvalu, sovereignty, and climate change: Considering Fenua, the archipelago, and emigration. Island Stud. J., 8 (1), 67-83.

Sultana, F., 2011: Suffering for water, suffering from water: Emotional geographies of resource access, control, and conflict. Geoforum, 42, 163-172, doi:10.1016/j.geoforum.2010.12.002.

- 2015: Emotional political ecology. The International Handbook of Political Ecology, R. Bryant, Ed., Edward Elgar Publishing, 633-645.

Sumaila, U. R., and Coauthors, 2012: Impacts of the Deepwater Horizon well blowout on the economics of the US Gulf fisheries. Can. J. Fish. Aquat. Sci., 69, 499-510, doi:10.1139/ f2011-171.

Taylor, K., S. Thorne, and J. L. Oliffe, 2015: It's a sentence, not a word: Insights from a keyword analysis in cancer communication. Qual. Health Res., 25, 110-121, doi:10.1177/ 1049732314549606.

Ulrich, R. S., 1983: Aesthetic and affective responses to natural environments. Human Behavior and Environment, Vol. 6, Behavior and Natural Environment, I. Altman and J. F. Wohlwill, Eds., Plenum, 85-125, doi:10.1007/978-1-4613-3539-9_4.

Woodward, K., and J. Lea, 2010: Geographies of affect. The SAGE Handbook of Social Geographies, S. J. Smith et al., Eds., SAGE Publications, 154-175.

Wutich, A., and K. Ragsdale, 2008: Water insecurity and emotional distress: Coping with supply, access, and seasonal variability of water in a Bolivian squatter settlement. Soc. Sci. Med., 67, 2116-2125, doi:10.1016/j.socscimed.2008.09.042. 